\title{
Skin Response Completion Status
}

National Cancer Institute

\section{Source}

National Cancer Institute. Skin Response Completion Status. NCI Thesaurus. Code C117684.

A term used to describe the state or condition of the completeness of the skin response data. 